\title{
"A Retrospective And Prospective Study of Epidemiological Factors, Clinico-Pathological Profile, And Treatment Plans in Patients of Oral Cavity Cancers Admitted In JA Group of Hospitals and GR Medical College Gwalior"
}

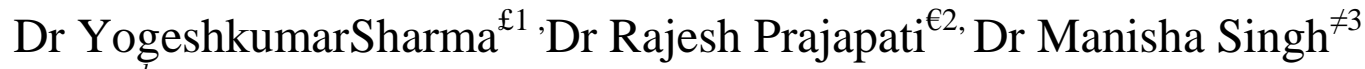 \\ ${ }^{I} £$ PG Student, Department Of Surgery, Gajra Raja Medical College, Gwalior \\ ${ }^{2} \epsilon$ Assistant Professor, Department Of Surgery, Gajra Raja Medical College, Gwalior \\ ${ }^{3} \neq$ Assistant Professor, Department Of Surgery, Gajra Raja Medical College, Gwalior
}

\section{Introduction}

Head and neck cancer is a heterogeneous group of tumors with differing clinical patterns. Worldwide it is considered to be the fifth most common cancer and ranking seventh in term of mortality due to cancers.Incidence of head and neck carcinomas varies greatly in different regions of the worldwhich isattributedto deficiency in documentation of developing countries.However recent data indicate an increasing trend in incidence of these cancers in the developing countries, most likely due to a higher exposure toalcohol and tobacco,health ignorance, poor access to health care facilities. Also in these countries head and neck carcinomas tend to present in advanced stages and have poor prognosis.

The head and neck cancers are mostly grouped according to their anatomical site i.e. oral cavity, nasal cavity and paranasal sinuses, nasopharynx, oropharynx, laryngopharynx and salivary glands. The oral cavity cancer is one of the most common neoplastic lesions of head and neck worldwide, whereas the cancer of gingivobuccal complex is the most common in Indian subcontinent. The widespread use of smokeless tobacco consumption is the main etiological factor which is quite prevalent in the northern states of Uttar Pradesh, Bihar and Gujarat. Various legislations have been initiated to curb this social menace and an attempt is being made to bring about a change in recent days. The etiology of oral cancer involves multiple factors and the most important are life stylefactors, such as cigarette smoking, alcohol consumption and betel quid chewing.

Treatment of oral cavity cancers depends on the specific sub-site of the tumor and primary tumor staging. It is also necessary to take into consideration the performance status of each patient, as treatment is very intense with multiple side effects. Patient with co-morbidities have poor survival, irrespective of the choice of treatment. Until advent of $20^{\text {th }}$ century, surgery was the only treatment available for these patients.Then radiotherapy was introduced and it was initially intended to replace surgery as treatment. This has not been the case however instead the two modalities were used together over the last century, but at the end of the last century chemotherapy in combination with radiotherapy became more common. Still surgery has an important role to play in management of these patients and over time surgeons have strived to produce less morbidity and disfigurement, by evolution of new techniques. Lower stage tumors of oral cavity are often treated with surgery alone while those of higher stages are treated with combined modalities.

In past none of the studies in our setup have tried to document the epidemiological and clinicpathological profile of oral cavity carcinoma patients in Indian setting especially the kind of population we are serving to in Central India. Performing this study is to document and analyse above mentioned aspects if these patients and to evaluate the treatments plans used in these patients in term of clinical outcome.

\section{Aims And Objectives}

1. To study the association of epidemiological factors in oral cavity cancers in our hospital.

2. To study the clinic pathological profile of patients with oral cavity cancers admitted in our hospital.

3. To study varioustreatment modalities for oral cavity cancer in our hospital.

\section{Material And Methods}

After obtaining approval from ethical committee, the present study entitled"A Retrospective And Prospective Study Of Epidemiological Factors, Clinico-Pathological Profile, And Treatment Plans In Patents Of Oral Cavity Cancers Admitted In JA Group Of Hospitals And GR Medical College Gwalior"is to be conducted on total 100 patients of oral cavity cancer admitted in JA group of hospitals and G R Medical College Gwalior(M.P.) during 2011 to 2016. Consent taken will be documented for patients presenting during the course of study. 
Sample size: 100 patients

Duration of study: one year

\section{Criteria for selection:}

- Patients admitted during the study period in GRMC and JA group of hospitals Gwalior having histopathologically proven malignancies of lip, anterior two third of tongue, buccal mucosa, retromolartrigone, gingiva and hard palate

Exclusion criteria: following subjects would be excluded from study-

- Prospective patients who are not willing to participate in the study .

- Patients having malignancies of head and neck other than oral cavity.

- Patients having recurrence

In all patients undergoing study, through examination of records will be undertaken for retrospective patients and a detailed history taking and examination will be performed in prospective patients. The treatment modality chosen and the final outcome of the patient would be taken into account. Biopsies of each patient wasperformed in outpatientdepartment and result obtained from department of pathology G.R. Medical College Gwalior (M.P.)

\section{Following points will be noted in each of these patients}

1. Demographic data- age, sex, socioeconomic class, occupation, education

2. History-presenting symptoms, duration of symptoms, history of alcohol consumption, smoking, gutkha chewing, significant medical history

3. Examination- general condition, orodental hygiene, tumor location, extent of tumor, palpable lymph node and their levels, premalignant lesion such as erythroplakia, leukoplakia.

4. Relevant investigations-basic blood investigations, imaging wherever applicable in form of CT head and neck and x-rays of maxilla and mandible bones

5. Histopathological type of malignancy

6. Treatment protocol plan followed

7. Final outcome of the patient

8. Follow-up as available

These observations will be tabulated and results will be deduced.Relevant statistical tests of significance will be applied wherever required, to analyse the association of particular factors.

\section{Observations And Results}

A total of 100 patients of oral cavity cancers admitted in Department of Surgery, G R Medical College and cancer ward J A Group of Hospitals, Gwalior were included in this study from Feb 2015 to Jan 2016 and following results were obtained:

1. Age

In the present study, the mean age of the study sample was $47.21( \pm 12.27)$ years ranging from 24 years to 78 years in different patients. The median age of the sample was 46.5 years. Most of the patients belonged to the 41-50 years of age group.

Table-1

Age distribution of patients

\begin{tabular}{|l|l|}
\hline Age & No of patients \\
\hline $21-30$ & 5 \\
\hline $31-40$ & 11 \\
\hline $41-50$ & 36 \\
\hline $51-60$ & 29 \\
\hline $61-70$ & 11 \\
\hline $71-80$ & 8 \\
\hline Total & 100 \\
\hline
\end{tabular}




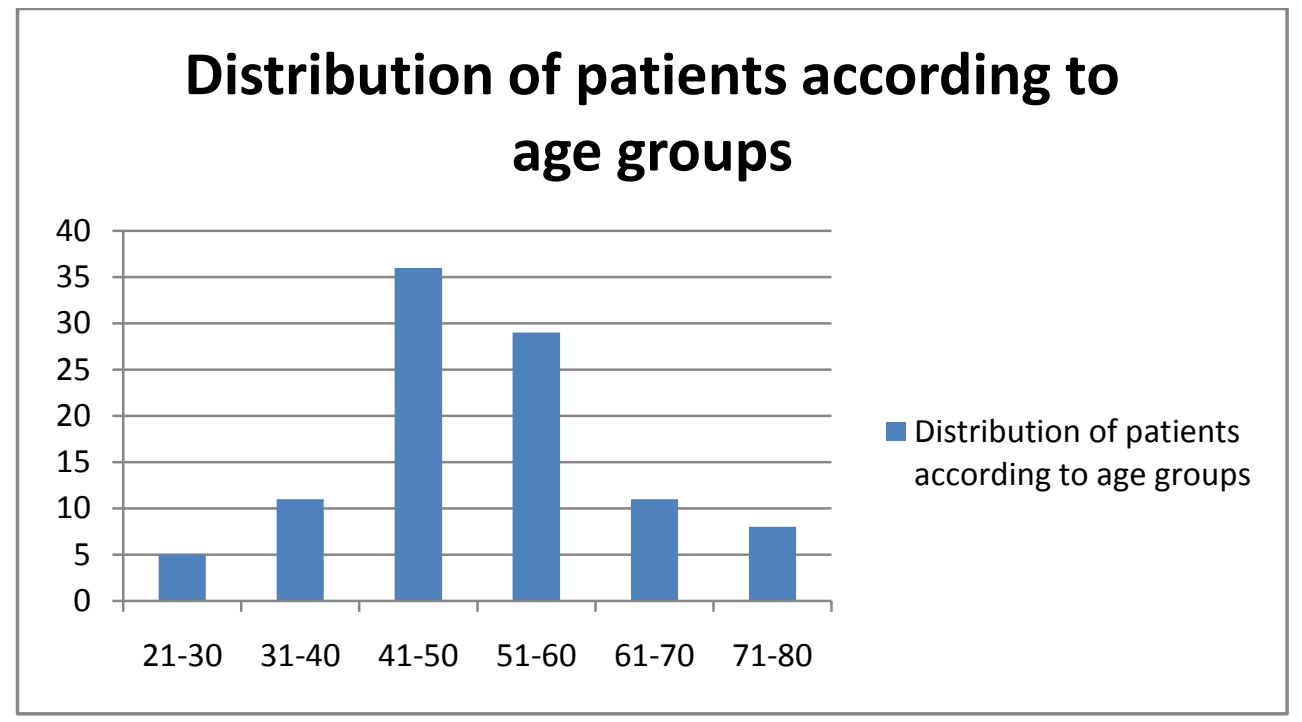

Graph1 Showing age distribution of the sample

\section{Gender}

The study sample had 94 males and 06 females among the patients showing male preponderance of oral cavity cancers.

Table-2 Sex Distribution Of Patients

\begin{tabular}{|l|l|l|}
\hline Sex & Male & Female \\
\hline No of patients & 94 & 6 \\
\hline
\end{tabular}

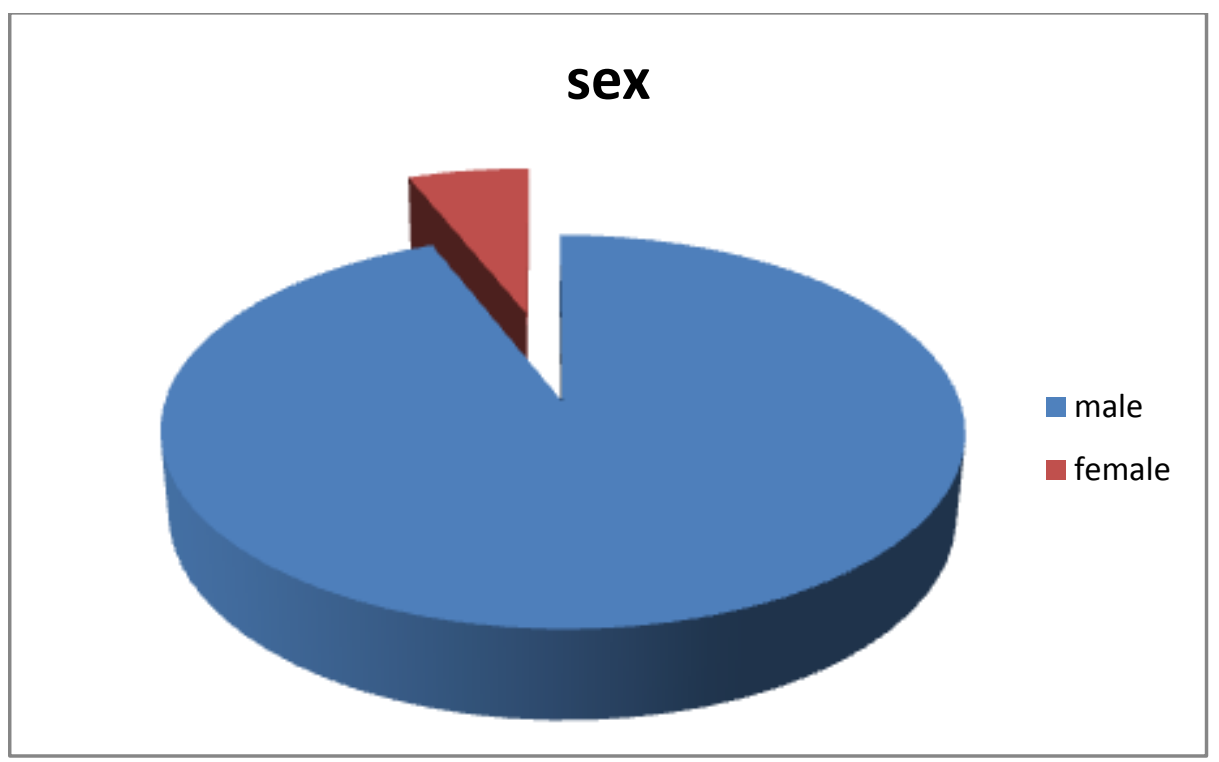

Graph 2Showing gender distribution of the sample

\section{Presenting complaints:}

In the present study out of the 100 patients, majority of the patients presented with main complaints of ulcer in oral cavity in $63 \%$, followed by foreign body sensation in $12 \%$, swelling in $11 \%$, pain in $8 \%$ of patients and difficulty in opening of mouth in $6 \%$ of patients of oral cavity cancers respectively. 
“A retrospective and prospective study of epidemiological factors, clinico-pathological profile, and ...

Table no. 3ShowingMain presenting complaints

\begin{tabular}{|l|l|}
\hline Main Presenting complaints & No of patients \\
\hline Ulcer & 63 \\
\hline Foreign body sensation & 12 \\
\hline Pain & 8 \\
\hline Swelling & 11 \\
\hline Difficulty in opening mouth & 6 \\
\hline
\end{tabular}

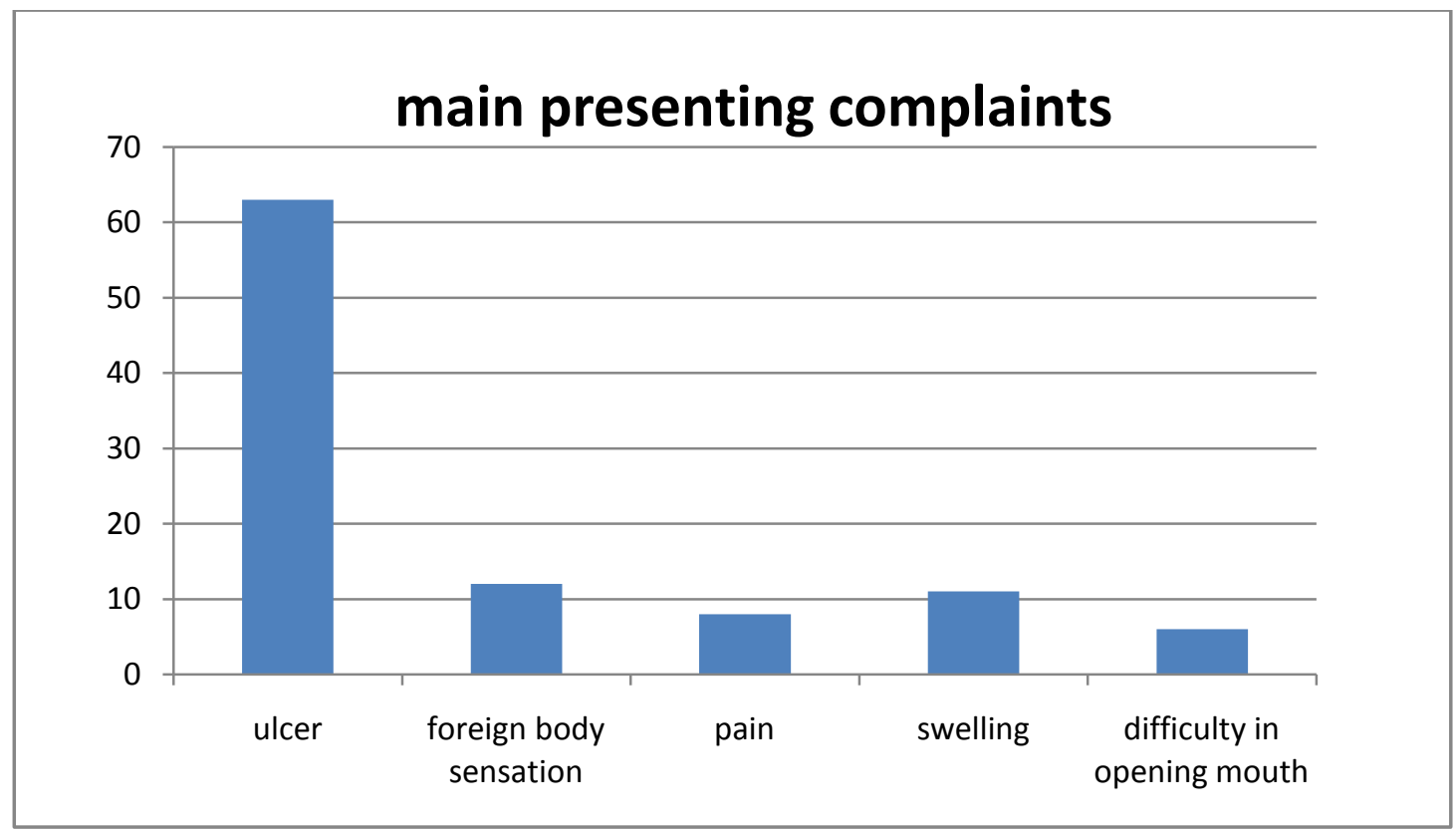

Graph 3 Showing main presenting complaints of the patients in study

\section{Substance abuse:}

In the present study out of the 100 patients, majority of the patients presented with substance abuse of tobacco chewing alone $45 \%$, smoking and tobacco abuse with 19\%, alcohol and tobacco $11 \%$, Alcohol, smoking $\&$ tobacco $10 \%$, smoking alone $8 \%$, alcohol and smoking $7 \%$ respectively while no patient had addiction of alcohol alone.

Table No.4Showing prevalence of substance abuse in study group

\begin{tabular}{|l|c|}
\hline \multicolumn{1}{|c|}{ Substance use } & No \\
\hline Alcohol & 0 \\
\hline Smoking & 8 \\
\hline Tobacco & 45 \\
\hline Alcohol+smoking & 7 \\
\hline Alcohol+tobacco & 11 \\
\hline Smoking+tobacco & 19 \\
\hline Alcohol+smoking+tobacco & 10 \\
\hline
\end{tabular}




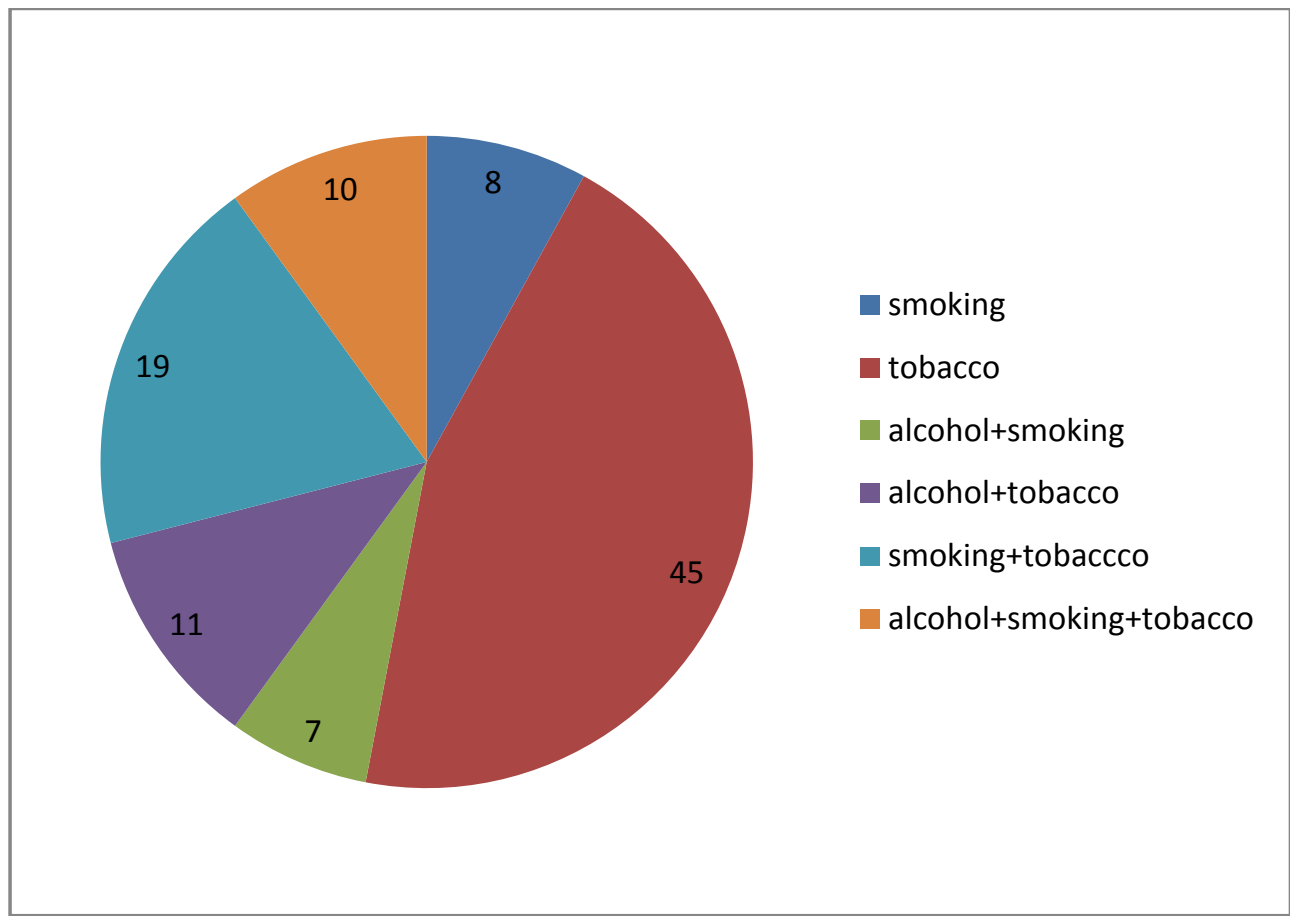

Graph 4 :Showing prevalence of substance abuse in study group

\section{General condition :}

In the present study out of the 100 patients, majority of the patients had average general condition(68\%), good GC (26\%) and poor GC (6\%).

Table No 5ShowingGeneral condition of the patient in the study group

\begin{tabular}{|c|c|}
\hline General Condition & No of patients \\
\hline Poor & 06 \\
\hline Avg & 68 \\
\hline Good & 26 \\
\hline
\end{tabular}

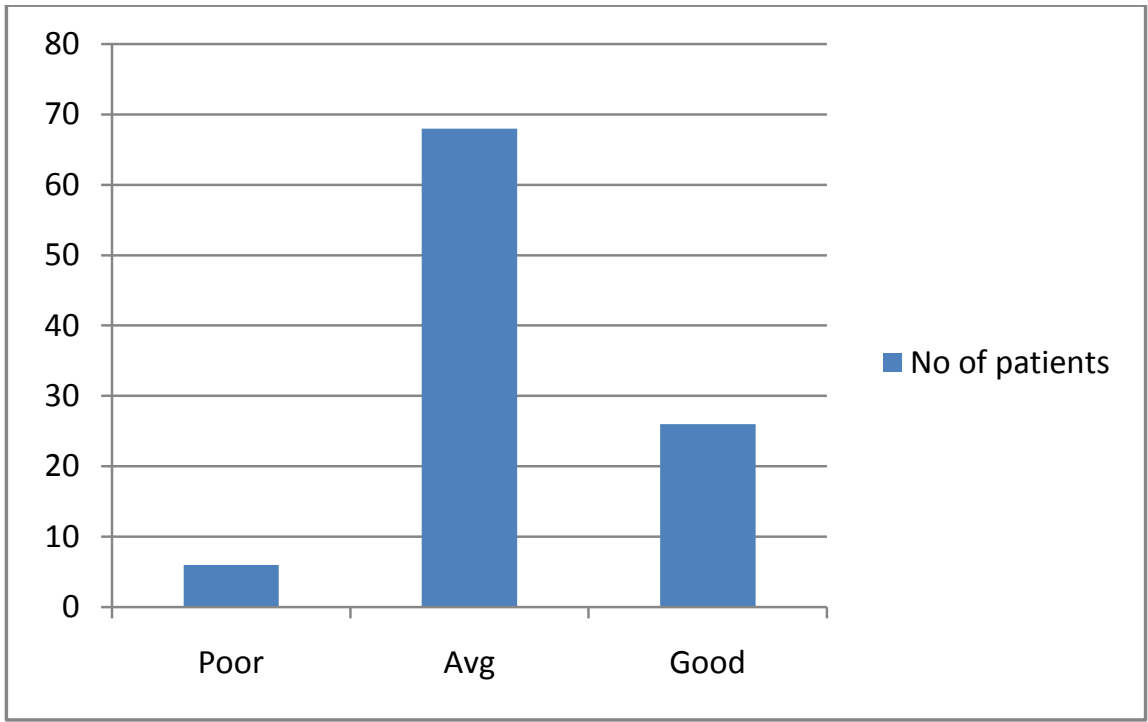

Graph no 5 showing general condition of the patients

\section{Orodental Hygiene}

In the present study out of the 100 patients, majority of the patients had poor orodental hygiene $(61 \%)$, average orodental hygiene (39\%) respectively while no patient having good orodental hygiene. 
Table no. 6Showing Orodental hygiene of the patient

\begin{tabular}{|c|c|}
\hline Orodental hygiene & No of patients \\
\hline Poor & 61 \\
\hline Average & 39 \\
\hline Good & 00 \\
\hline
\end{tabular}

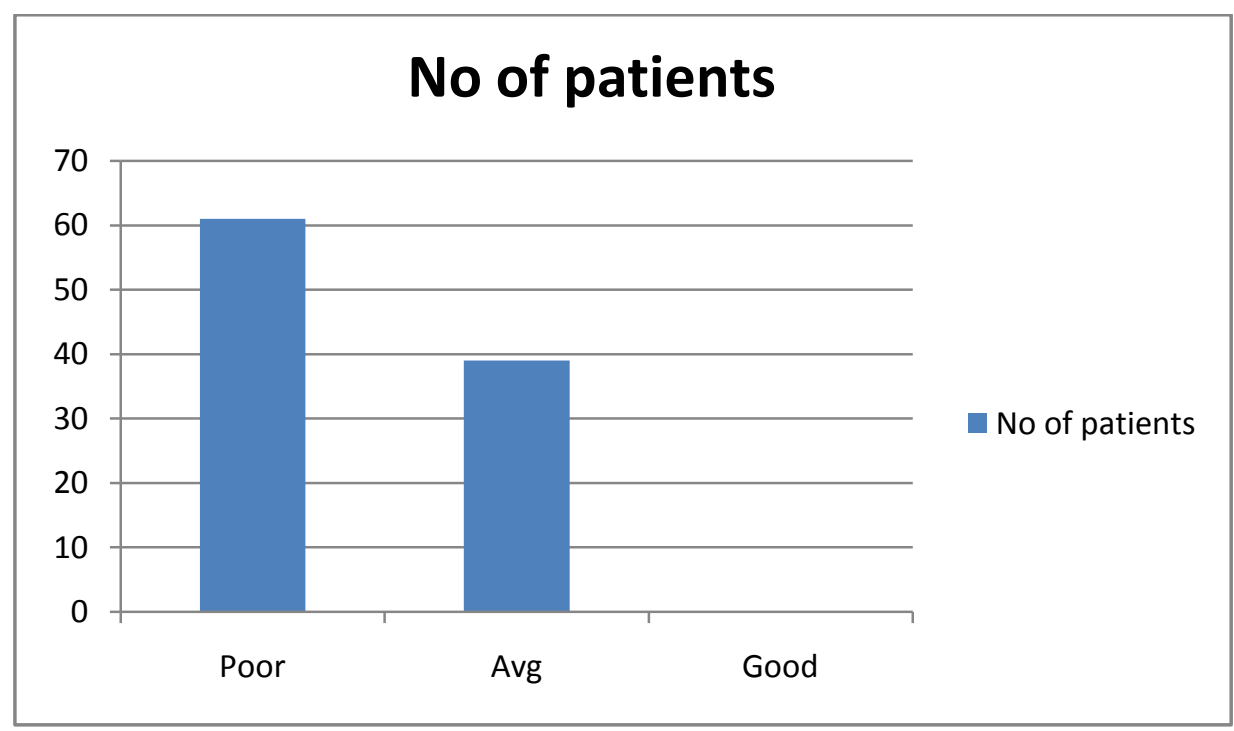

Graph6 :ShowingOrodental hygiene of the patients

\section{Location Of Tumor}

In the present study out of the 100 patients, most common site for ca oral cavity was found to be buccal mucosa $(39 \%)$ followed by tongue(33\%), gingiva buccal sulcus $(22 \%)$, lip (5\%), floor of mouth (1\%) respectively while no patient found with tumor location on hard palate and retromolartrigone.

Table no 7ShowingLocation of tumor in oral cavity

\begin{tabular}{|l|c|}
\hline \multicolumn{1}{|c|}{ Location of tumor } & Number \\
\hline Lip & 5 \\
\hline Tongue & 33 \\
\hline Buccal mucosa & 39 \\
\hline Gingivobaccal sulcus & 22 \\
\hline Hard palate & 0 \\
\hline Retromolartrigone & 0 \\
\hline Floor of mouth & 1 \\
\hline
\end{tabular}

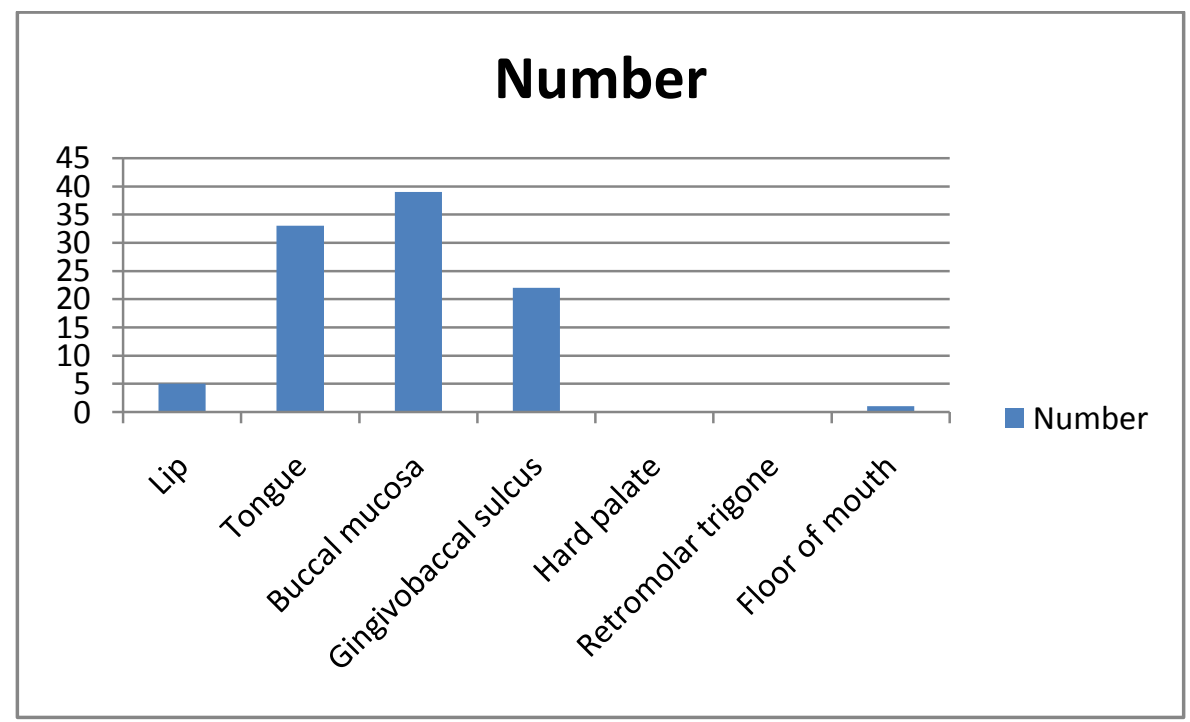

Graph 7: ShowingLocation of tumor in oral cavity 
“A retrospective and prospective study of epidemiological factors, clinico-pathological profile, and ...

\section{Palpable lymph node}

In the present study out of the 100 patients, $41 \%$ patients having clinically palpable regional lymph node. $59 \%$ patients do not have any clinically palpable regional lymph node.

Table no. 8Showing Lymph node status in patient

\begin{tabular}{|l|l|l|}
\hline Palpable lymphnode & Present & Absent \\
\hline No of patients & 41 & 59 \\
\hline
\end{tabular}

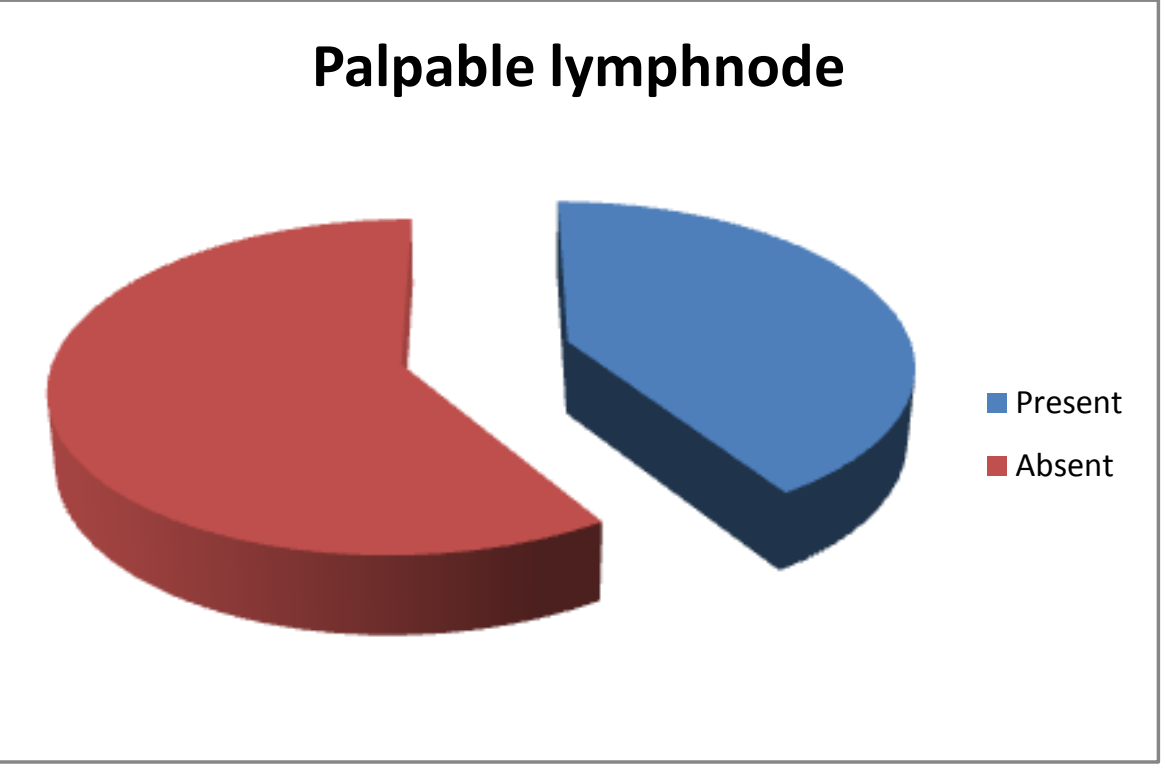

Graph8 :Showing Lymph node status in patient

\section{Plane X Ray Mandible and Maxilla}

Bone involvement; In the present study out of the 100 patients, $36 \%$ patients having involvement of bone either mandible or maxilla depending on tumor location on plane x-ray or CT scan .64\% patients do not have involvement of bone either mandible or maxilla depending on tumor location on plane x-ray or CT scan .

Table no. 9Showing Involvement of bone in study sample

\begin{tabular}{|l|l|c|}
\hline $\begin{array}{c}\text { Plane } \mathbf{x} \text { ray mandible and } \\
\text { maxilla }\end{array}$ & Bone involve present & Bone involve absent \\
\hline No of patients & 36 & 64 \\
\hline
\end{tabular}

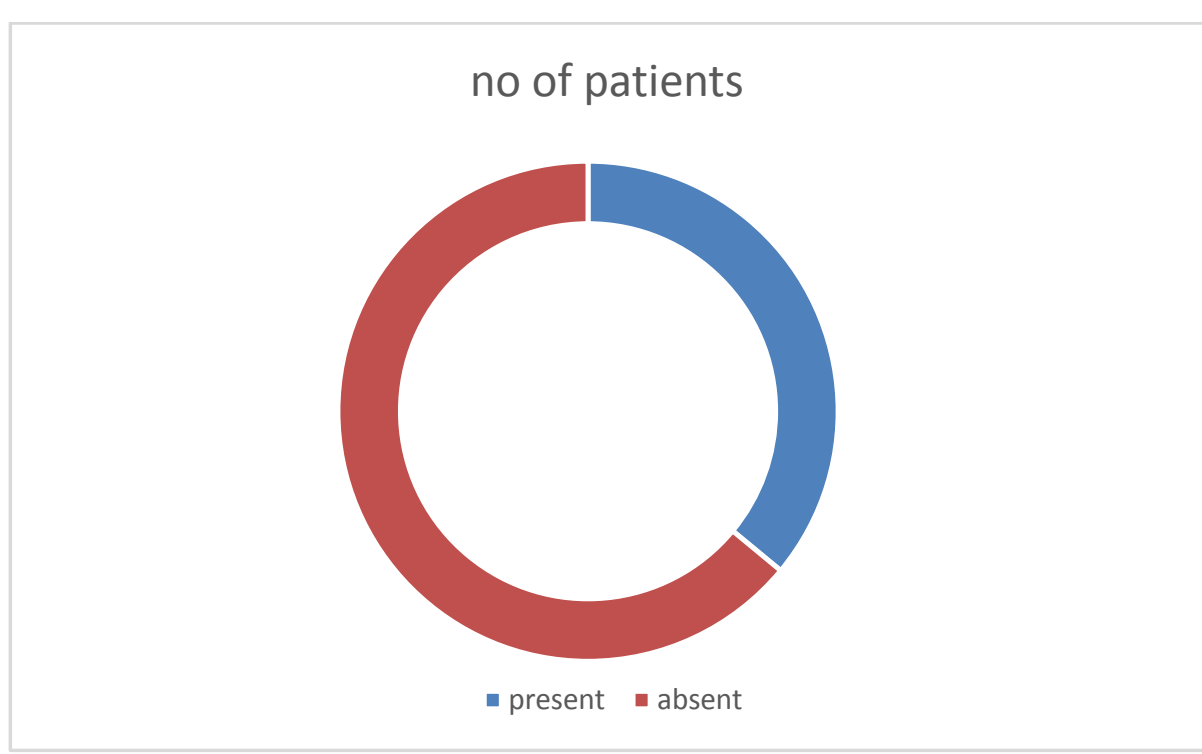

Graph9 :Showing Involvement of bone in study sample 
“A retrospective and prospective study of epidemiological factors, clinico-pathological profile, and ...

\section{Histopathology report;}

In the present study out of the 100 patients, on their histopathology report $98 \%$ patients found to have squamous cell carcinoma while minority of patients $(2 \%)$ had basal cell carcinoma.

Table no. 10

Showing Histopathology report of tumor in study sample

\begin{tabular}{|c|c|c|}
\hline Histopathology report & Squamous cell carcinoma & Basal cell carcinoma \\
\hline No of patients & 98 & 2 \\
\hline
\end{tabular}

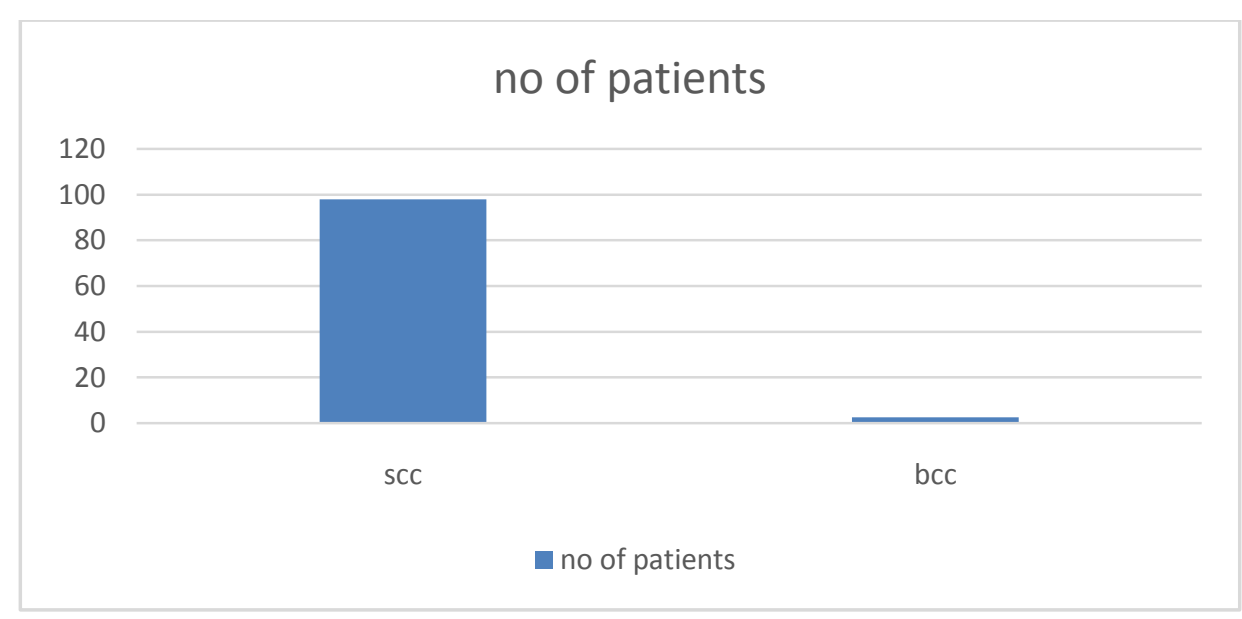

Graph 10 :Showing Histopathology report of tumor in study sample

\section{Treatment plans :}

In the present study out of the 100 patients, majority of the patients was treated with surgery and radiotherapy $(42 \%)$, followed by radiotherapy and chemotherapy (18\%), surgery alone (14\%), radiotherapy alone (12\%), surgery, radiotherapy and chemotherapy (12\%), surgery and chemotherapy (2\%) respectively while none of the patient was treated with chemotherapy alone.

Table no. 11ShowingVarious treatment plans in patients with oral cavity cancers

\begin{tabular}{|l|c|}
\hline \multicolumn{1}{|c|}{ Treatment plans } & No of patients \\
\hline Surgery alone & 14 \\
\hline Radiotherapy alone & 12 \\
\hline Chemotherapy alone & 0 \\
\hline Surgery + radiotherapy & 42 \\
\hline Surgery+ chemotherapy & 2 \\
\hline Radiotherapy + chemotherapy & 18 \\
\hline $\begin{array}{l}\text { Surgery+ radiotherapy+ } \\
\text { chemotherapy }\end{array}$ & 12 \\
\hline
\end{tabular}




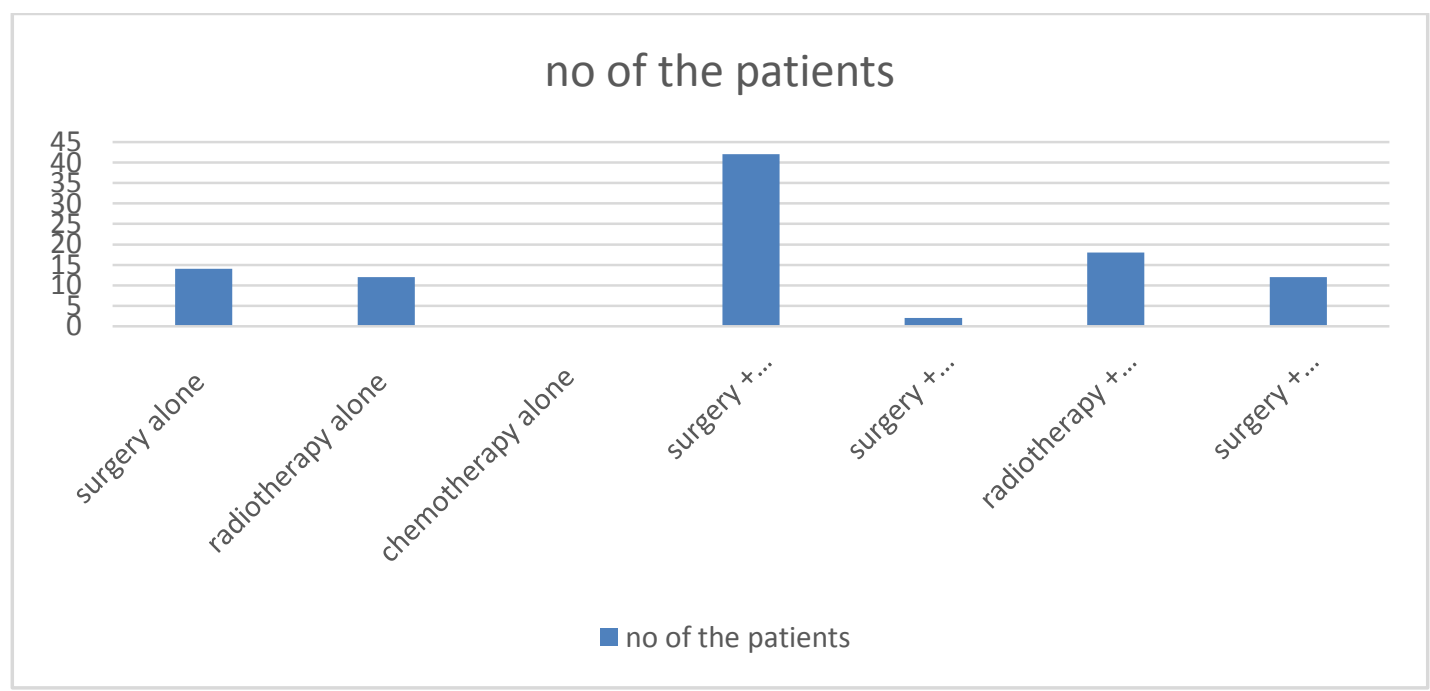

Graph 11:ShowingVarious treatment plans in patients with oral cavity cancers

\section{Discussion}

Overall, head and neck cancer accounts for more than 500,000 cases annually worldwide. The cradle of head and neck oncology was located in ancient Egypt and Greece. The first tumors treated in the head and neck were either cutaneous malignancies or cancers were on the mucosal surfaces of the oral cavity. The origin, diagnosis and treatment of more deeply situated tumors of the larynx and hypopharynx remained obscure for many centuries. The medieval age brought little progress to medicine in general, and in head and neck oncology in particular, due to religious concerns. Renaissance medicine was characterized by advances in medicine and oncology made by systematic dissection studies of normal and pathologic anatomy. The 19th and 20th century reflect the development of head and neck oncology in the era of science based medicine. Almost all of our current understanding of head and neck oncology, our diagnostic methods and treatment strategies have been developed in these two centuries. Many oncologic problems, which occupy our minds today, were also concerns of our medical ancestors.

In this study, the recorded data of 100 consecutive patients of admitted to our hospital for oral cavity cancers was analysed in terms of epidemiological factors, clinico-pathological profile, and treatment plans The discussion of our observations is as following:

\section{Age Distribution:}

In the present study, the mean age of the study sample was $47.21( \pm 12.27)$ years ranging from 24 years to 78 years in different patients. The median age of the sample was 46.5 years. Most of the patients belonged to the $45-50$ years of age group.

\section{Gender}

The study sample had 94 males and 06 females among the patients showing male preponderance of oral cavity cancers.

\section{Presenting Complaints:}

In the present study out of the 100 patients, majority of the patients presented with main complaints of ulcer in oral cavity in $63 \%$, foreign body sensation in $12 \%$, pain in $8 \%$ most common symptom, swelling in $11 \%$ of patients and difficulty in opening of mouth in $6 \%$ of patients of oral cavity cancers.

\section{Substance Abuse:}

In the present study out of the 100 patients, majority of the patients presented with substance abuse of tobacco chewing alone $45 \%$, smoking and tobacco abuse with 19\%, alcohol and tobacco $11 \%$, Alcohol, smoking \& tobacco $10 \%$, smoking alone $8 \%$, alcohol and smoking $7 \%$ respectively while no patient had addiction of alcohol alone. 


\section{General Condition:}

In the present study out of the 100 patients, majority of the patients had average general condition(68\%), good GC (26\%) and poor GC (6\%).

\section{Orodental Hygiene}

In the present study out of the 100 patients, majority of the patients had poor orodental hygiene (61\%), average orodental hygiene (39\%) respectively while no patient having good orodental hygiene.

\section{Location of Tumor}

In the present study out of the 100 patients, most common site for CA oral cavity was found to be buccal mucosa (39\%) followed by tongue(33\%), gingiva buccal sulcus (22\%), lip (5\%), floor of mouth (1\%) respectively while no patient found with tumor location on hard palate and retromolartrigone.

\section{Palpable Lymph Node:}

In the present study out of the 100 patients, $41 \%$ patients having clinically palpable regional lymph node. $59 \%$ patients do not have any clinically palpable regional lymph node.

\section{Plane X-Ray Mandible And Maxilla (Bone Involvement)}

In the present study out of the 100 patients, $36 \%$ patients having involvement of bone either mandible or maxilla depending on tumor location on plane x-ray or CT scan.64\% patients do not have involvement of bone either mandible or maxilla depending on tumor location on plane $\mathrm{x}$-ray or $\mathrm{CT}$ scans.

\section{Histopathology Report;}

In the present study out of the 100 patients, on their histopathology report $98 \%$ patients found to have squamous cell carcinoma while minority of patients $(2 \%)$ had basal cell carcinoma.

\section{Treatment Plans:}

In the present study out of the 100 patients, majority of the patients was treated with surgery and radiotherapy $(42 \%)$, followed by radiotherapy and chemotherapy (18\%), surgery alone (14\%), radiotherapy alone $(12 \%)$, surgery, radiotherapy and chemotherapy (12\%), surgery and chemotherapy (2\%) respectively while none of the patient was treated with chemotherapy alone. Combined clinics that include surgeons, oncologists, and support staff usually have an agreed treatment policy and offer the best outcomes. Oral squamous cell carcinoma (OSCC) currently is treated largely by surgery and/or irradiation, although few unequivocal controlled trials of treatment modalities have been conducted. Photodynamic and chemotherapy have occasional applications, and there is an increased use of chemotherapy,including targeted therapy.

\section{Conclusion}

- Patients with oral cavity cancers should be advocated to lead a healthy lifestyle and society should develop awareness against the use of tobacco, smoking and betel quid chewing due to their strong association with oral cavity cancers.

- Patients with oral cavity cancers should be told about the importance of maintaining a good orodental hygiene and maintenance of a healthy life style as it curbs the risk of oral cavity cancer in the majority of the patients.

- Patients should be counselled about various treatment modalities that can be offered to the patients and their associated side effects and importance of long term follow up keeping in mind the gravity of the disease and its curability.

\section{Limitations of Our Study}

The present study was done on 100 patients with taking into consideration certain pre-defined clinicopathological and epidemiological variables. However, we do recommend for replication of this study in larger samples and a greater number of factors affecting outcome should be taken into account. This can help to ensure better treatment profiles for patients with oral cavity cancers.

\section{VII.Summary}

Head and neck cancers constitute a major proportion of surgical oncology clinics. The incidence of head and neck cancers are increasing due to increasing exposure to the risk factors, we are better able to investigate these conditions with the help of contrast enhanced CT and MRI . The therapeutic options available 
are not limited to surgery and new protocols for radiotherapy and chemotherapy are being used.In this study, various epidemiological factors, clinico-pathological profile, and treatment plans in patients of oral cavity cancers was studied and the results of the study can be summarized as following:

1. Most of the patients belonged to the 41-50 years of age group. (mean age 47.21 years) and males outnumbered females in the study sample (M:F=15.67:1).

2. Most common complaint by the patients in the study group was of ulcer in oral cavity in $63 \%$ followed by foreign body sensation in $12 \%$, pain in $8 \%$, swelling in $11 \%$ of patients and difficulty in opening of mouth in $6 \%$ of patients.

3. Majority of the patients presented with substance abuse of tobacco chewing alone $45 \%$, smoking and tobacco abuse with $19 \%$, alcohol and tobacco $11 \%$, Alcohol, smoking \& tobacco 10\%, smoking alone $8 \%$, alcohol and smoking $7 \%$ respectively while no patient had addiction of alcohol alone.

4. Majority of the patients had average general condition(68\%), good GC (26\%) and poor GC (6\%) while orodental hygiene $(61 \%)$ was poor in majority of the patients.

5. Most common site for CA oral cavity was found to be buccal mucosa (39\%) followed by tongue(33\%), gingiva buccal sulcus (22\%), lip (5\%), floor of mouth $(1 \%)$ respectively while no patient found with tumor location on hard palate and retromolartrigone.

6. In the present study out of the 100 patients, $41 \%$ patients having clinically palpable regional lymph nodeWhile $36 \%$ patients having involvement of bone either mandible or maxilla depending on tumor location on plane x-ray or CT scan.

7.98\% patients were found to have squamous cell carcinoma while minority of patients $(2 \%)$ were found to have basal cell carcinoma on their histopathological reports.

8. Majority of the patients in our study were treated by surgery and radiotherapy.

\section{References}

[1]. Argiris A, Karamouzis MV, Raben D, Ferris RL. Head and neck cancer. Lancet. 2008;371:1695-1709.

[2]. Ferlay J, Shin HR, Bray F, Forman D, Mathers C, Parkin DM. GLOBOCAN 2008 v2.0, Cancer incidence and mortality worldwide: IARC CancerBase No. 10 [Internet]. Lyon, France: International Agency for Research on Cancer; 2010

[3]. Joshi P, Nair S, Chaturvedi P, Nair D, Agarwal JP, D'Cruz AK. Delay in seeking specialized care for oral cancers: Experience from a tertiary cancer center. Indian J Cancer.2014 Apr-Jun; 51(2):95-7

[4]. Misra S, Chaturvedi A, MisraNC.Management of gingivobuccal complex cancer.Ann R CollSurg Engl. 2008 Oct; 90(7):546-53.

[5]. Gourin CG, Boyce BJ, Vaught CC, Burkhead LM, Podolsky RH. Effect of comorbidity on post-treatment quality of life scores in patients with head and neck squamous cell carcinoma. Laryngoscope. 2009 May;119(5):907-14

[6]. Gourin CG, McAfee WJ, Neyman KM. Effect of comorbidity on quality of life and treatment selection in patients with squamous cell carcinoma of the head and neck. Laryngoscope. 2005;115:1371-1375.

[7]. Colledge L. Treatment of Cancer of Pharynx and Larynx. Br Med J 1938;2:167- 168.

[8]. Gibson, M.K., Forastiere, A.A. Multidisciplinary approaches in the management of advanced head and neck tumors: state of the art. CurrOpinOncol. 2004;16:220-224.

[9]. Liu JC, Shah JP. Surgical technique refinements in head and neck oncologic surgery. J SurgOncol 2010;101:661-668.

[10]. deBree R, Rinaldo A, GendenEMet al. Modern reconstruction techniques for oral and pharyngeal defects after tumor resection. Eur Arch Otorhinolaryngol 2008;265:1-9.

[11]. Chaturvedi AK, Anderson WF, Lortet-Tieulent J, et al. Worldwide trends in incidence rates for oral cavity and oropharyngeal cancers. J ClinOncol 2013; 31:4550.

[12]. Jemal A, Bray F, Center MM, et al. Global cancer statistics. CA Cancer J Clin 2011; 61:69.

[13]. Folz BJ, Silver CE, Rinaldo A, Fagan JJ, Pratt LW, Weir N, Seitz D, FerlitoA."An outline of the history of head and neck oncology".OralOncol. 2008Jan;44(1):2-9.

[14]. Consolidated Report of Hospital Based Cancer Registries : 2007-2011, accessed on 22 september, 2016 <www.icmr.nic.in/ncrp/HBRC_Report_2007_2011/Main.htm>

[15]. Oral cancer incidence by age, 2016, accessed on 22 september, 2016<http://www.ons.gov.uk/ons/rel/vsob1/cancer-statisticsregistrations--england--series-mb1-/index.html>

[16]. Ajit Auluck, et al," Population-based incidence trends of oropharyngeal and oral cavity cancers by sex among the poorest and underprivileged populations"BMC Cancer201414:316

[17]. .Radoï L, Paget-Bailly S, Cyr D, Papadopoulos A, Guida F, Tarnaud C, Menvielle G, Schmaus A, Cénée S, Carton M, LapôtreLedoux B, Delafosse P, Stücker I, Luce D." Body mass index, body mass change, and risk of oral cavity cancer: results of a large population-based case-control study, the ICARE study"Cancer Causes Control. 2013 Jul;24(7):1437-48. doi: 10.1007/s10552-0130223-z. Epub 2013 May 16.

[18]. Oral Cavity and Oropharyngeal Cancer , accessed $\quad$ on 22 september, 2016<http://www.cancer.org/cancer/oralcavityandoropharyngealcancer/detailedguide/oral-cavity-and-oropharyngeal-cancer-signssymptoms>,"

[19]. Ko, Y.-C., Huang, Y.-L., Lee, C.-H., Chen, M.-J., Lin, L.-M. and Tsai, C.-C. (1995), Betel quid chewing, cigarette smoking and alcohol consumption related to oral cancer in Taiwan. Journal of Oral Pathology \& Medicine, 24: 450-453.

[20]. Z naor, A., Brennan, P., Gajalakshmi, V., Mathew, A., Shanta, V., Varghese, C. and Boffetta, P. (2003), Independent and combined effects of tobacco smoking, chewing and alcohol drinking on the risk of oral, pharyngeal and esophageal cancers in Indian men. Int. J. Cancer, 105: 681-686.

[21]. N Homann", J Tillonen", et al, "Poor dental status increases acetaldehyde production from ethanol in saliva: a possible link to increased oral cancer risk among heavy drinkers "Oral OncologyVolume 37, Issue 2, February 2001, Pages 153-158

[22]. Addala L, Pentapati CK, Thavanati PKR, et al (2012). Risk factor profiles of head, neck cancer patients of Andhra Pradesh, India. Indian J Cancer, 49, 215-9.

[23]. Iype EM, Pandey M, Mathew A, et al (2001a). Oral cancer among patients under the age of 35 years. J Postgrad Med, 47 , $171-6$. 
“A retrospective and prospective study of epidemiological factors, clinico-pathological profile, and ...

[24]. Iamaroon A, Pongsiriwet S, Pattanaporn K, et al (2004). Analysis of 587 cases of oral squamous cell carcinoma in northern Thailand with a focus on young people. Int J Oral MaxillofacSurg, 33, 84-8

[25]. Sherin N, Simi T, Shameena PM, et al (2008). Changing trends in oral cancer. India J Cancer, 45, 93-6

[26]. H Narendra et al., "Prevalence and pattern of nodal metastasis in pT4 gingivobuccal cancers and its implications for treatment", Indian Journal of Cancer, Vol. 47, No. 3, July-September, 2010, pp. 328-331

[27]. Gerhard W. Goerres, Daniel T. Schmid, Bernhard Schuknecht, and Gerold K. Eyrich," Bone Invasion in Patients with Oral Cavity Cancer: Comparison of Conventional CT with PET/CT and SPECT/CT",Radiology2005237:1, 281-287

[28]. O'Brien CJ, Carter RL, Soo KC, Barr LC, Hamlyn PJ, Shaw HJ. Invasion of the mandible by squamous carcinomas of the oral cavity and oropharynx. Head Neck Surg1986;8:247-256

[29]. Consolidated Report of Hospital Based Cancer Registries : 2007-2011, accessed on 22 september, 2016 <www.icmr.nic.in/ncrp/HBRC_Report_2007_2011/Main.htm>

[30]. Vanderveken OM, Szturz P, Specenier P, Merlano MC, Benasso M, Van Gestel D, et al. Gemcitabine-Based Chemoradiation in the Treatment of Locally Advanced Head and Neck Cancer: Systematic Review of Literature and Meta-Analysi

[31]. Nwizu T, Adelstein D. Pharmacotherapy of head and neck cancer.ExpertOpinPharmacot 